\title{
Giant Invasive Pituitary Adenoma Differential Diagnosis and Therapeutic Management (A Case Report and Literature Review)
}

\author{
Abderrahmane Rafiq, Liévin Panu, Abdelhamid Jehri,Tarek Mesbahi, Abdelhakim Lakhdar
}

\section{ABSTRACT}

Giant pituitary adenomas represent a significant surgical and diagnostic challenge; giant pituitary adenomas with a development that goes beyond the sella can be difficult to manage surgically due to the narrowness of the space and the proximity of important anatomical structures which are at risk according to the surgical approach and its extension in the cavum with absence of endocrine sign can be misinterpreted as cancer of the cavum which was the case for our patient refer to the neurosurgery department after 3 inconclusive biopsies by nasofibroscopy and after visual deterioration.

Keywords: Case report, endoscopy endonasal surgery, giant, invasive, pituitary adenoma.

\section{INTRODUCTION}

Giant pituitary adenomas can be defined as adenomas with a vertical height exceeding $4 \mathrm{~cm}$. the large size of these tumors and the frequent involvement of neurovascular structures make surgery a real challenge; the problems of surgery are specific and very different from those of small tumors. the suprasellar cistern, the interpeduncular fossa, the third ventricle, the cavernous sinus, the sphenoid sinus and the clivus are the neighboring structures frequently invaded by this kind of tumors [1], [2]. Here we report a case report of giant pituitary adenoma with extension into sphenoid sinus and nasopharynx.

\section{Clinical CASE}

\section{A. Anamnesis}

A 22-year-old patient with a history of diffuse goiter on levothyrox, without a particular surgical history who had presented amenorrhea with galactorrhea for 1 year. The patient did not consult until her condition worsened due to the installation of an incomplete intracranial hypertension syndrome made up of cepalees with a sudden decline in visual acuity; what motivated the patient to consult an
Submitted: November 7,2021

Published: February 15, 2022

ISSN: 2593-8339

DOI: $10.24018 /$ ejmed.2022.4.1.1137

\section{A. Rafiq*}

Department of Neurosurgery, UHC Ibn Rochd, Casablanca, Morocco.

(e-mail: meryemfarisrafiq @gmail.com)

L.Panu

Department of Neurosurgery, UHC Ibn

Rochd, Casablanca, Morocco.

A. Jehri

Department of Neurosurgery, UHC Ibn

Rochd, Casablanca, Morocco.

T.Mesbahi

Department of Neurosurgery, UHC Ibn

Rochd, Casablanca, Morocco

A. Lakhdar

Department of Neurosurgery, UHC Ibn

Rochd, Casablanca, Morocco.

*Corresponding Author ophthalmologist asking for a cerebral scanner then refer to an ear, nose and throat (ENT) care.

\section{PHYSICAL EXAMINATION}

The admission examination revealed bilateral galactorrhea at minimal pressure; the rest of the somatic examination is unremarkable.

\section{PARAClinical EXAmination}

CT scan revealed a tissue process in the middle floor of the base of the skull: sphenoidal origin? nasopharynx?.

MRI: anterior pituitary increases of heterogeneous size exceeding at the level sphenoidal sinus with 3 nodular lesions, the largest of which $11.3 \times 8 \mathrm{~mm}$.

A biopsy of the cavum by rhinocavoscopy: caval mucosa exuded without signs of neoplasia or specificity

MRI revealed anterior pituitary increases in heterogeneous size protruding at the level sphenoidal sinus with 3 nodular lesions including the largest $11.3 \times 8 \mathrm{~mm}$. Then finally refer to neurosurgery. 


\section{THERAPEUTIC INTERVENTION}

Under general anesthesia with orotracheal intubation in dorsal decubitus: incision of the right nasal mucosa; detachment of the nasal septum; visualization of the rostrum and its removal; opening of the floor of the sphenoid sinus after scopic control; discovery of a white extradural process that $\mathrm{s}$ extends to the sphenoidal sinus; excisional biopsy was performed then replacement of bone fragments then placement of two nasal tompals.

\section{FOLLOW-UP AND OUTCOMES}

The postoperative course was marked by peripheral facial paralysis recovered with corticosteroid therapy; a disappearance of headaches and stabilization of visual acuity then the patient was referred to endocrinology for additional treatment.

\section{DISCUSSION}

Pituitary adenomas are benign tumors with slowly growing. They make up about $10-15 \%$ of all intracranial tumors [3]. These benign tumors represent $14.6 \%$ of all pituitary tumors [4] and can grow to large dimensions without being detected for several reasons. Giant pituitary tumors are non-functional and manifest themselves through visual impairment including amputation of the visual field, visual obscuration, blindness, and in rare cases hormonally active. Despite the giant size, these tumors are most often histologically benign. The diagnosis of giant pituitary adenomas is generally made on the basis of clinical features and anatomical extensions assessed on imaging, so diagnostic surgery is of little relevance [5].

The symptoms are not correlated with the size of the tumor the objective is the maximum safe resection of the tumor to decompress the optical pathways and preserve pituitary function. The giant pituitary adenoma may transgress the limit of the sellar diaphragm and invade the arteries of the plygon of Willis. In these cases, the tumor spread through the subarachnoid spaces of the brain and invades the arteries and perforators. The exact site of dural dehiscence is not known. Tumor invasion corresponds to that of a squamous cell tumor, it spreads in the available spaces, engulfing the blood vessels and cranial nerves without actually invading them, does not compromise the lumen of the artery and only causes moderate travel. In both cases in this group, the goal of surgery was only a biopsy, as radical tumor resection was difficult and dissection between the perforators could compromise them [2].

Medical treatment, and possibly radiation therapy, is usually crucial for long-term tumor control. Surgery is the first step in treatment; this goal is achieved through various surgical approaches. Recently, endoscopy has become the approach of choice for many pituitary surgeons. In general, the transsphenoidal approach is preferred because it causes few complications. this approach adequately exposes and provides safe access to the cavernous sinus. Despite a growing trend towards an endoscopic endonasal approach in recent years.

Endoscopic endonasal surgery allows panoramic visualization and wider access to the base of the skull compared to the transsphenoidal microscopic approach to the speculum which gives tunnel vision very limited access.

The indications for endoscopic endonasal surgery have been extended thanks to technological advances such as angulated endoscopes, specialized instrumentation, image guidance and neurophysiological monitoring of the brain and cranial nerves [6].

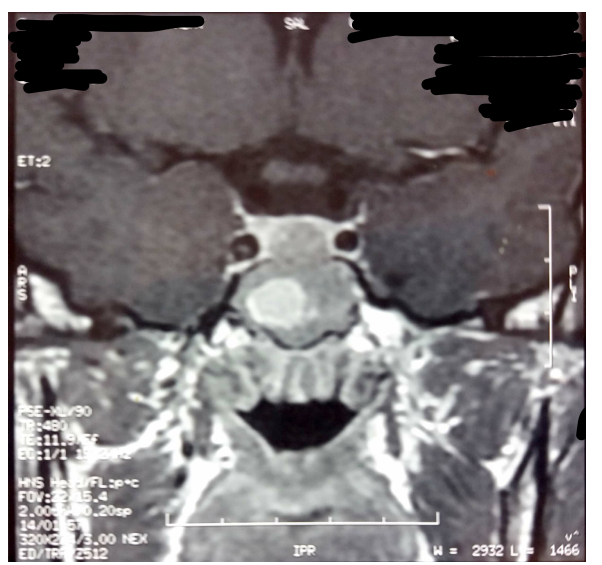

Fig. 1. Brain MRI coronal cut in T1 injected.

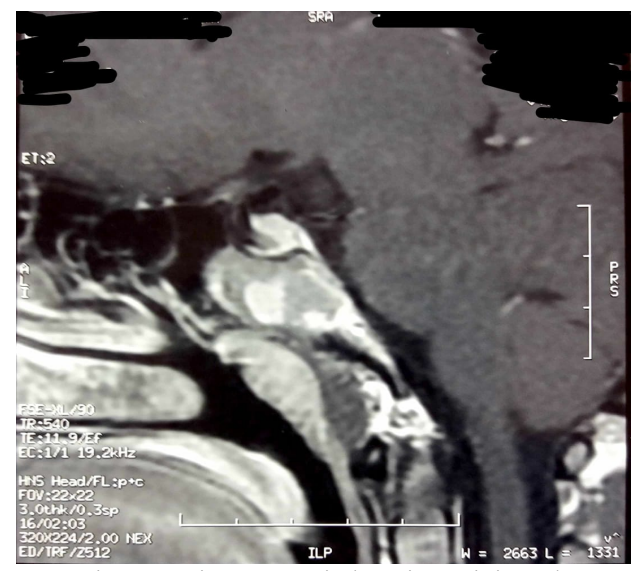

Fig. 2. Brain MRI sagital cut in T1 injected.

\section{CONCLUSIONS}

Pituitary adenomas can grow to such large dimensions without being detected, so they should always be looked for in visual obscuration, loss of field or blindness, even in the absence of endocrine signs.

Transsphenoidal surgery is the preferred approach due to lower morbidity and complications. Despite a growing trend towards an endoscopic endonasal approach in recent years, due to the evolution of operating technology

\section{REFERENCES}

[1] Goel A, Nadkarni T. Surgical management of giant pituitary tumoursa study of 30 cases. Acta Neurochir (Wien). 1996; 138: 1042-1049.

[2] Goel A, Nadkarni T, Muzumdar D, Desai K, Phalke U, Sharma P. Giant pituitary tumors: a study based on surgical treatment of 118 cases. Surg Neurol. 2004; 61: 436-445.

[3] Kaltsas GA, Nomikos P, Kontogeorgos G, Buchfelder M, Grossman AB. Clinical review: diagnosis and management of pituitary carcinomas. J Clin Endocrinol Metab. 2005; 90: 3089-3099. 
[4] Knosp E, Steiner E, Kitz K, Matula C. Pituitary Adenomas with Invasion of the Cavernous Sinus Space. Neurosurgery. 1993; 33: 610 617.

[5] Gondim JA, Almeida JPC, Albuquerque LAF, Gomes EF, Schops M. Giant pituitary adenomas: surgical outcomes of 50 cases operated on by the endonasal endoscopic approach. World Neurosurgery. 2014; 82(1-2): e281-e290.

[6] Koutourousiou M, Gardner PA, Fernandez-Miranda JC, Paluzzi A, Wang EW, et al. Endoscopic endonasal surgery for giant pituitary adenomas: advantages and limitations. Journal of Neurosurgery, 2013; 118(3): 621-631 